\title{
Bipolar Radiofrequency (RF) in Pediatric Tonsillectomy: A Prospective Controlled Study
}

\author{
Hossam S. Elsherif ${ }^{*}$, Saad Elzayat ${ }^{2}$ \\ ${ }^{1}$ ENT Department, Tanta University, Tanta, Egypt \\ ${ }^{2}$ ENT Department, Kafr Elsheikh University, Kafr Elsheikh, Egypt \\ Email: *hossam_elsherif@yahoo.com
}

How to cite this paper: Elsherif, H.S. and Elzayat, S. (2020) Bipolar Radiofrequency (RF) in Pediatric Tonsillectomy: A Prospective Controlled Study. International Journal of Otolaryngology and Head \& Neck Surgery, 9, 124-132.

https://doi.org/10.4236/ijohns.2020.94016

Received: March 13, 2020

Accepted: June 29, 2020

Published: July 2, 2020

Copyright $\odot 2020$ by author(s) and Scientific Research Publishing Inc. This work is licensed under the Creative Commons Attribution International License (CC BY 4.0).

http://creativecommons.org/licenses/by/4.0/

\section{Open Access}

\begin{abstract}
Background/Hypothesis: Tonsillectomy operation is one of the most frequently performed procedures in otolaryngology practice. Many tonsillectomy techniques have been used as a trial to improve post-operative results especially those related to pain and bleeding. We aimed to assess safety of bipolar radiofrequency tonsillectomy in pediatric patients, comparing its results with the classic cold steel technique. Study Design: Prospective controlled study. Methods: Two hundred cases were included in this study. They were placed into 2 groups which underwent tonsillectomy by 2 different techniques with comparison between the results of both groups. Results: Bipolar radiofrequency had a better result regarding time of the operation and intra-operative bleeding with similar results regarding post-operative pain and follow up. Conclusion: Bipolar radiofrequency is an effective and safe technique in total tonsillectomy with acceptable intra-operative and post-operative results regarding pain and bleeding and can be used in pediatric population with no major morbidities.
\end{abstract}

\section{Keywords}

Tonsillectomy, Radiofrequency, Pediatric, Bipolar

\section{Introduction}

In the recent years, many technologies have been developed in performing tonsillectomy, searching for the ideal technique regarding the intra-operative blood loss, operation time, post-operative pain, and hemorrhage [1] [2].

The increasing concern about tonsillectomy is owned to its high rate as it is one of the commonest pediatric operations all over the world [3]. Pain following electro-cauterization techniques compared to cold steel technique, remains con- 
troversy. Many studies prefer classic cold steel technique as it is accompanied by less pain [4].

Radiofrequency unit allows the passage of electrical current in the tissue. The surface of the probe doesn't heat, as in electrocautery; rather, the tissue heat due to passage of radiofrequency current through it. Thus it produces a temperature controlled and predictable effect on the desired tissue, which decreases the collateral damage and post-operative pain [5]. This technique was reported to be shorter in operating time, with minimal intra-operative blood loss, and with no additional increase in post-operative pain and hemorrhage when compared with the classic technique [6].

In this study, we tried to assess the safety of using bipolar radiofrequency (RF) in pediatric tonsillectomy compared to classic cold steel technique and their associated morbidities.

\section{Patients and Methods}

This prospective randomized study was done during the period from April 2017 to April 2019 in the ENT Department, Dar-Elshefa hospital, Tanta, Egypt. Two hundred consecutive patients planned for tonsillectomy were included in the study. They were randomly placed into 2 equal groups (100 cases each). One case was performed by bipolar RF and the next case was performed by the cold steel technique. The parents of the cases signed an informed consent, accepting their participation in this research.

In this study we included all cases with recurrent tonsillitis or obstructive sleep apnea due to tonsillar hypertrophy according to the indications determined by the American Academy of Otolaryngology-Head and Neck Surgery.

Cases with associated adenoidectomy were excluded. We also excluded cases with unequal tonsillar hypertrophy, previous history of peritonsillar abscess, history of rheumatic fever, any general condition problem as diabetes mellitus and cases that refused the bipolar RF technique.

Preoperative $\mathrm{CBC}$ and assessment of the bleeding profile together with pediatric consultation were done in the preoperative preparation which included also general and ENT examinations.

In all cases, the operation was done under general anesthesia after fasting for 8 hours, using the standard Rose position and the Boyel Davis' mouth gag. Any case with fever was postponed.

In group $\mathrm{A}$, we used a bipolar RF forceps, connected to a RF apparatus model Ellman Surgitron 4 MHZ (Ellman International, New York, USA) by which cutting and dissection with coagulation were done in the same time with minimal diffuse heating to the surrounding tissue. The power was adjusted to a power grade 40 in a bipolar mode.

In the other group, we used the classic cold steel technique in which dissection and hemostasis were done without any cauterization. Hemostasis was done by gauze compression, ligatures or silk stitches. 
In both groups total tonsillectomy was done. Operation time was calculated from the placement of the mouth gag till its removal. After the operation, the patient were discharged the next day on a medical schedule of analgesic as paracetamol (15 mg/kg/dose) every 6 hours and amoxicillin $(50 \mathrm{mg} / \mathrm{kg} /$ day).

The parents were educated about the diet. Hot, spicy, dry and acidic foods should be avoided with encouraging taking ice chips and freezes.

Follow up visits were on the $3^{\text {rd }}, 7^{\text {th }}, 10^{\text {th }}$ and after one month. In our study we focused on time of the operation, amount of intra-operative bleeding, occurrence of post-operative bleeding, fever, dehydration, pain in the first day, third day, seventh day via visual analogue scale (VAS), the day of return to normal diet, the day of return to normal activity, number of days on analgesic schedule and one month follow up with observation of healing. We compared both groups in all of these items.

The data was collected and analyzed using a software program SPSS (Statistical Package for the Social Science, version 22, IBM, and Armonk, New York).

\section{Results}

Two hundred cases were divided into 2 groups, group A (radifrequency) and group B (cold steel), with 100 cases in each group. The age of cases in both groups ranged between one and five years old. Mean age in group A was $3.05 \pm$ 1.07 years old, however, the mean age in group B was $3.26 \pm 1.04$. They were 40 males and 60 females in group A. However, in group B they were 27 males and 73 females. No significant difference was found between both groups as regards age and sex (Table 1).

The time of operation in group A was $14.68 \pm 1.55$ minutes; however in group $B$, it was $31.87 \pm 3.05$ minutes. The difference in the time of the operation between the 2 groups was strongly statically significant ( $\mathrm{p}$ value $<0.0001$ ) (Figure $1)$.

Total amount of intra-operative blood loss was $23.56 \pm 3.58 \mathrm{ml}$, while in group B it was $52.1 \pm 8.08 \mathrm{ml}$. The difference between the 2 groups in the intra-operative blood loss was strongly statistically significant ( $\mathrm{p}$ value $<0.0001$ ). Post-operative bleeding occurred in 2 cases in group A and 3 cases in group B, which was statically insignificant ( $\mathrm{p}$ value $=0.65$ ) (Figure 2 ).

Post-operative dehydration occurred in 7 cases in group A and 6 cases in group B with no statistically significant difference between the two groups ( $\mathrm{p}$ value $=0.77$ ). Post-operative fever occurred in 9 cases in group A and 7 cases in group B with no statistically significant difference between the two groups ( $\mathrm{p}$ value $=0.60)($ Table 2$)$.

According to VAS, the median pain in the first day in both groups was 4 with no statistically significant difference between the two groups ( $\mathrm{p}$ value $=0.27$ ). In the $3^{\text {rd }}$ day, the median pain was 3 in both groups with no statistically significant difference between the two groups ( $\mathrm{p}$ value $=0.23$ ). In the $7^{\text {th }}$ day, the pain was 1 in group A and group B with no statistically significant difference between the 
two groups ( $\mathrm{p}$ value $=0.04$ ). The total number of days of need to use analgesics was $5.23 \pm 0.81$ in group $A$, while it was $5.17 \pm 0.87$, with no statistically significant difference between the two groups ( $\mathrm{p}$ value $=0.62$ ). The cases returned to the normal diet after $7.37 \pm 0.85$ days in group $\mathrm{A}$, while they returned to the normal diet after $7.24 \pm 0.69$ days in group $B$, with no statistically significant difference between the two groups ( $\mathrm{p}$ value $=0.24$ ). The cases returned to the normal activity after $3.68 \pm 1.12$ days in group $\mathrm{A}$, while they returned to the normal activity after $3.45 \pm 1.167$ days in group $B$, with no statistically significant difference between the two groups ( $p$ value $=0.15$ ) Figure 3, Table 2.

In the post-operative follow up visit one month after operation there was complete healing in the all cases (100\%) in group A, however 3 cases in group B showed residual ligatures, the difference was statistically insignificant ( $\mathrm{p}$ value $=$ $0.08)$.

Table 1. Demographic data.

\begin{tabular}{|c|c|c|c|c|}
\hline \multirow{3}{*}{$\begin{array}{c}\text { Demographic } \\
\text { data }\end{array}$} & \multicolumn{2}{|c|}{ Groups } & \multicolumn{2}{|c|}{ Test } \\
\hline & $\begin{array}{c}\text { group A } \\
\text { (radifrequency) }\end{array}$ & $\begin{array}{c}\text { group B } \\
\text { (cold steel), }\end{array}$ & \multirow[t]{2}{*}{$\chi^{2} / \mathrm{t}$} & \multirow{2}{*}{$\mathrm{p}$} \\
\hline & $\mathrm{N}=100(\%)$ & $\mathrm{N}=100(\%)$ & & \\
\hline \multicolumn{5}{|l|}{ Gender } \\
\hline Female & $60(60)$ & $73(73)$ & \multirow{2}{*}{0.457} & \multirow{2}{*}{0.499} \\
\hline Male & $40(40)$ & $27(27)$ & & \\
\hline \multicolumn{5}{|l|}{ Age (years) } \\
\hline Mean \pm SD & $3.05 \pm 1.07$ & $3.26 \pm 1.04$ & \multirow{2}{*}{-0.477} & \multirow{2}{*}{0.635} \\
\hline Range & $2-5$ & $2-5$ & & \\
\hline
\end{tabular}

Table 2. Results.

\begin{tabular}{|c|c|c|c|}
\hline Parameter & $\begin{array}{l}\text { Radiofrequecy group } \\
(\text { mean } \pm \mathrm{SD})\end{array}$ & $\begin{array}{l}\text { Cold steel group } \\
(\text { mean } \pm \mathrm{SD})\end{array}$ & P-value \\
\hline time of operation (minutes) & $14.68 \pm 1.5562$ & $31.87 \pm 3.0572$ & $<0.0001$ \\
\hline amount of intra-operative blood loss (ml) & $23.56 \pm 3.59$ & $52.1 \pm 8.08$ & $<0.0001$ \\
\hline Post-operative bleeding (cases) & 2 & 3 & 0.65 \\
\hline Post-operative dehydration (cases) & 7 & 6 & 0.77 \\
\hline Post-operative fever (cases) & 9 & 7 & 0.60 \\
\hline median pain in the first day (VAS) & 4 & 4 & 0.27 \\
\hline median pain in the $3^{\text {rd }}$ day (VAS) & 3 & 3 & 0.23 \\
\hline median pain in the $7^{\text {th }}$ day (VAS) & 1 & 1 & 0.04 \\
\hline Days of analgesics use (days) & $5.23 \pm 0.81$ & $5.17 \pm 0.87$ & 0.62 \\
\hline Days needed to return to normal diet (days) & $7.37 \pm 0.84$ & $7.24 \pm 0.69$ & 0.24 \\
\hline $\begin{array}{l}\text { Days needed to return to normal activity } \\
\text { (days) }\end{array}$ & $3.68 \pm 1.12$ & $3.45 \pm 1.17$ & 0.16 \\
\hline Healing after one month (cases) & 100 & 97 & 0.08 \\
\hline
\end{tabular}




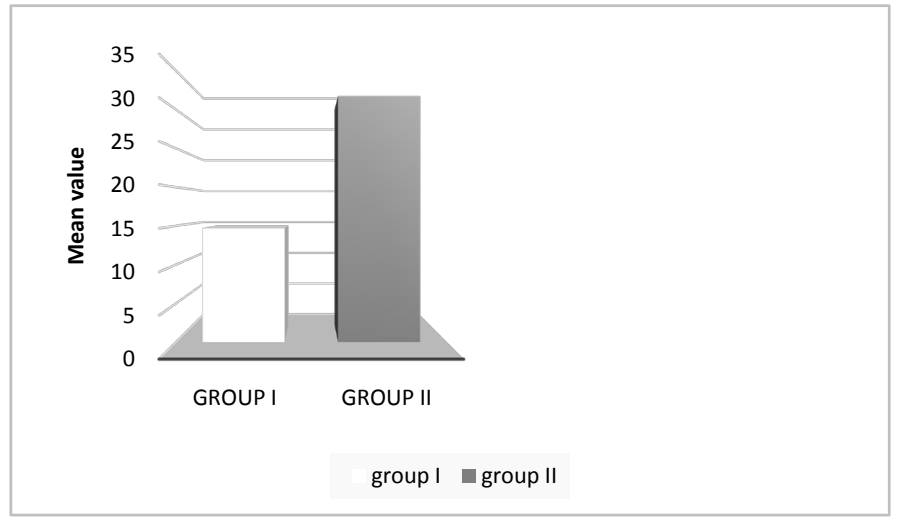

Figure 1. Operative Time for both surgical methods.

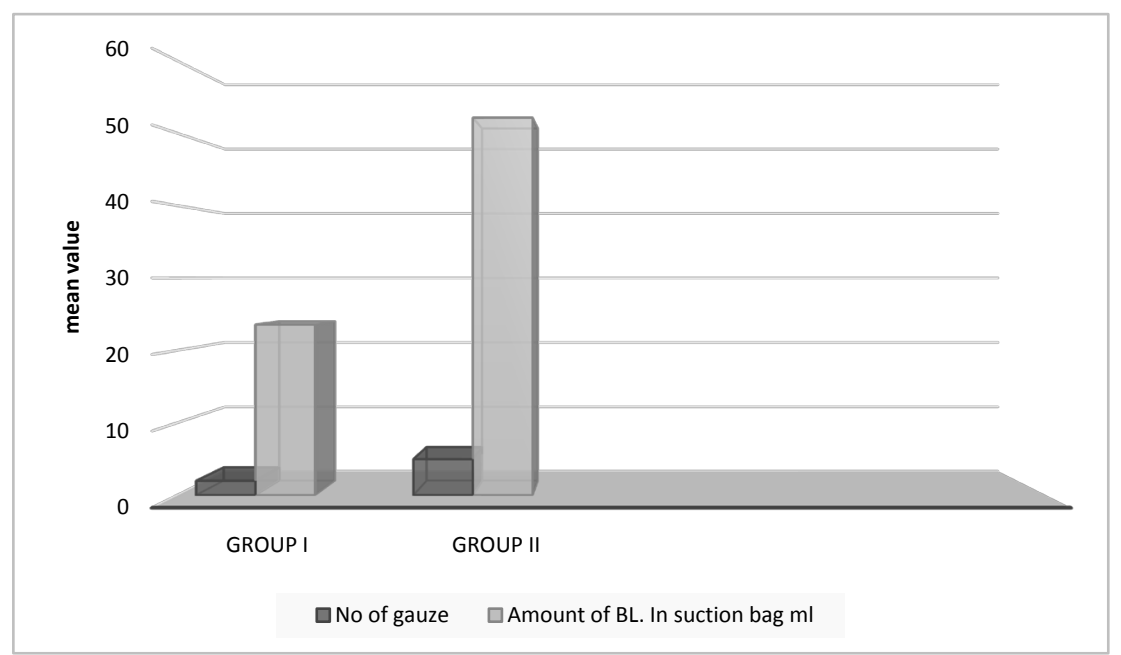

Figure 2. Intraoperative blood loss for both surgical methods.

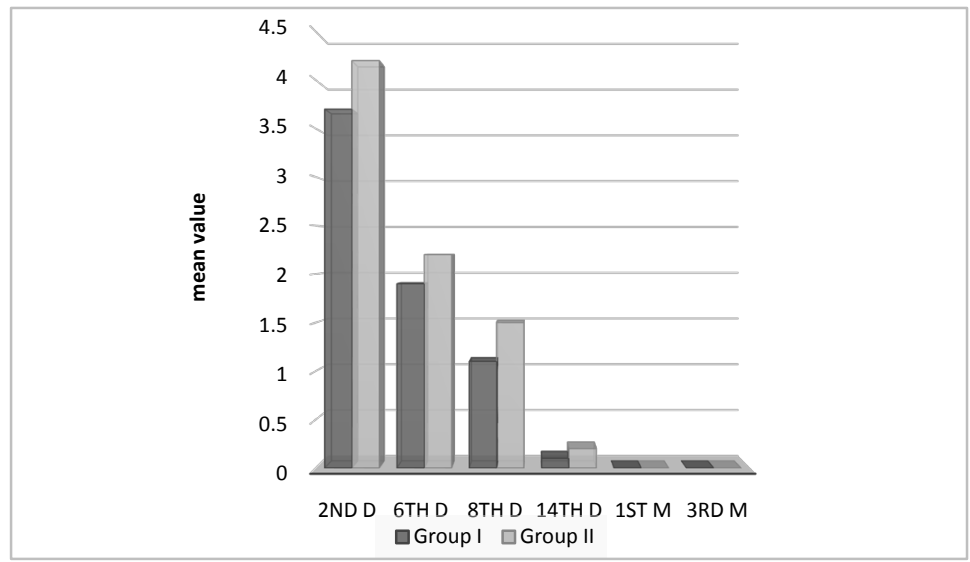

Figure 3. Postoperative Visual Analog Scale (VAS) results of patients in both groups.

\section{Discussion}

Tonsillectomy is one of the commonest operations all over the world [3]. Pain and bleeding are the most important post-operative morbidities [7]. As a trial to decrease the post-operative morbidities, many techniques has been developed as 
cold steel, monopolar dissection, $\mathrm{CO}_{2}$ laser, etc., with no upper hand of one technique over the others [8]. Pain following the operation is due to exposure of the nerve endings of the glossopharyngeal nerve and vagus nerve causing muscle spasm with each swallowing [9]. Bipolar RF is a new elecro-surgery which can used in total removal of the tonsils causing plasma field due to ions disintegration, which prevent diffuse heating, thus protect the surrounding tissue and results in less harm and pain. Many studies have been done aiming to find the best technique with less consequences. Toma et al., studied postoperative morbidity in adults after cold dissection tonsillectomy, pain was high on the ${ }^{\text {th }}$ day and continued beyond one week. Function was significantly reduced with many patients still not returned to work (78\%) till the $9^{\text {th }}$ day. Ninety percent of patients complained of swallowing problems in the first 5 days [10]. Radiofrequency was used in reduction of the size of the tonsils, this was accompanied by less pain as there was no exposure of the capsule, but may be complicated by recurrence due to hyperplasia of the tonsillar remnants. Nelson, made a study about RF tonsillar ablation, there were no attacks of bleeding and patients returned to normal activity within 1 to 2 days. He also noted a $70.8 \%$ reduction in tonsil size with an average airway enlargement of 54.5\% [11] [12]. Ericsson et al., compared RF tonsillotomy with cold steel tonsillectomy in improving quality of life in young adults (16 - 25 years old) with obstructive or infectious tonsil problems. Only the bulging parts of the tonsils were removed in the RF group (31 cases). Both techniques showed significant improvements on quality of life, infections, and obstructive problems one year after surgery, indicating that both surgical methods are equally effective [13]. In the other hand, other hot methods have been used as coblation with different results. El Tahan et al., has used coblation in adenoidectomy comparing it with the conventional method. He found that time of operation was shorter in conventional method [14]. In our study, we used bipolar $\mathrm{RF}$ in total removal of the tonsils without exposure of the capsule trying to decrease pain and overcoming the tonsillar re-hyperplasia following tonsillar ablation. We aimed at assessment of the safety of RF comparing it to cold steel technique which is considered the classic one. The total number of cases was 200 cases, divided into 2 groups, group A (RF) and group B (cold steel), with 100 cases in each group. The age of cases in both groups ranged between one year to five years old. Mean age in group A was $3.05 \pm 1.0671$ years old, however, the mean age in group B was $3.26 \pm 1.04078$ with the p value between the 2 groups is 0.16047 which is statically insignificant. They were 40 males and 60 females in group A. however in group B they were 27 males and 73 females. We have chosen choose young age group as it is the commonest group undergoing tonsillectomy, with no significant demographic difference between the 2 groups. The time of operation in group A was $14.68 \pm 1.55$ minutes, however in group $B$, it was $31.87 \pm 3.05$ minutes. The difference in the time of the operation between the 2 groups was strongly statically significant ( $\mathrm{p}$ value $<0.0001$ ) being shorter in group A. Total amount of intra-operative blood loss was $23.56 \pm 3.58$ $\mathrm{ml}$, while in group $\mathrm{B}$, it was $52.1 \pm 8.08 \mathrm{ml}$. The difference between the 2 groups 
in the intra-operative blood loss was strongly statically significant ( $\mathrm{p}$ value $<$ 0.0001). This indicates that RF is a simple easy technique with less bleeding. Post-operative bleeding occurred in 2 cases in group A and 3 cases in group B, which was statically insignificant ( $\mathrm{p}$ value was 0.65 ) between the 2 groups. All the cases with secondary bleeding were managed conservatively, except a case in group B, which was in the same day of the operation and needed control of bleeding under general anesthesia. Post-operative dehydration occurred in 7 cases in group A and 6 cases in group B, with no statistically significant difference between the two groups ( $p$ value $=0.77$ ). All cases were managed by I.V fluids and encouraged oral fluid intake with no major consequences as it was mild dehydration in all cases. Post-operative fever occurred in 9 cases in group A, while it occurred in 7 cases in group B which was statically insignificant between the groups ( $\mathrm{p}$ value $=0.60$ ). Most of them were due to dehydration. According to VAS, the median pain in the first day in both groups was 4 , which was statically insignificant between the 2 groups ( $p$ value $=0.27$ ). In the 3 rd day, the median pain was 3 in both groups, while it was 3 which was statically insignificant between the 2 groups ( $p$ value $=0.22$ ). In the 7 th day, the pain was 1 in group A and group B which was statically insignificant ( $\mathrm{p}$ value $=0.045$ ). The total number of days of need to use analgesics was $5.23 \pm 0.81$ in group $A$, while it was $5.17 \pm 0.87$ in group $B$, with no statistically significant difference between the two groups ( $\mathrm{p}$ value $=0.61$ ). The cases returned to the normal diet after 7.37 \pm 0.84 days in group A, while they returned to the normal diet after 7.24 \pm 0.69 days in group B, which was statically insignificant between the 2 groups ( $p$ value $=0.24$ ). The cases returned to the normal activity after $3.68 \pm 1.12$ days in group A, while they returned to the normal activity after $3.45 \pm 1.167$ days in group $B$, which was statically insignificant between the 2 groups ( $\mathrm{p}$ value $=0.15$ ). In the post-operative follow up visit one month after operation, there was complete healing in the all cases (100\%) of group A, however 3 cases in group B showed residual ligatures. Post-operative results of both groups regarding pain indicates that bipolar RF does not cause disruption of the tonsillar capsule with less irritation of the surrounding nerve endings and less diffuse heating, resulting in acceptable pain after tonsillectomy operation, with no risk of recurrence as in the ablation technique.

\section{Conclusion}

Bipolar radiofrequency is a safe and effective technique in total tonsillectomy with acceptable intra-operative and post-operative results regarding pain and bleeding and can be used in pediatric population with no major morbidities.

\section{Ethical Approval}

All procedures performed in studies involving human participants were in accordance with the ethical standards of the institutional research committee and with the 1964 Helsinki declaration and its later amendments or comparable ethical standards. 


\section{Consent}

Formal consent was signed by the parents of the children for sharing in this research.

\section{Availability of Data and Materials}

The datasets used and/or analysed during the current study are available from the corresponding author on reasonable request.

\section{Funding}

The authors have no funding or financial relationships to disclose.

\section{Authors' Contributions}

S.Z. methodology, idea formulation and reference collection H.E. review writing and revision, editing final draft.

\section{Acknowledgements}

Not applicable.

\section{Conflicts of Interest}

The authors declare no conflicts of interest regarding the publication of this paper.

\section{References}

[1] Leinbach, R.F., et al. (2003) Hot versus Cold Tonsillectomy: A Systematic Review of the Literature. Otolaryngology-Head and Neck Surgery, 129, 360-364. https://doi.org/10.1016/S0194-5998(03)00729-0

[2] Paradise, J.L. (2003) Tonsillectomy and Adenoidectomy. In: Bluestone, C.D., Ed., Pediatric Otolaryngology, 4th Edition, Saunders, Philadelphia, 1210-1222.

[3] Curtin, J.M. (1987) The History of Tonsil and Adenoid Surgery. Otolaryngologic Clinics of North America, 20, 415-419.

[4] Randall, D.A. and Hoffer, M.E. (1998) Complications of Tonsillectomy and Adenoidectomy. Otolaryngology-Head and Neck Surgery, 118, 61-68. https://doi.org/10.1016/S0194-5998(98)70376-6

[5] Smith, T.L. and Smith, J.M. (2001) Electrosurgery in Otolaryngology-Head and Neck Surgery: Principles, Advances, and Complications. Laryngoscope, 111, 769-780. https://doi.org/10.1097/00005537-200105000-00004

[6] Ragab, S.M. (2005) Bipolar Radiofrequency Dissection Tonsillectomy: A Prospective Randomized Trial. Otolaryngology-Head and Neck Surgery, 133, 961-965. https://doi.org/10.1016/j.otohns.2005.07.037

[7] Nunez, D.A., Provan, J. and Crawford, M. (2000) Postoperative Tonsillectomy Pain in Pediatric Patients: Electrocautery (Hot) vs. Cold Dissection and Snare Tonsillectomy: A Randomized Trial. Archives of Otorhinolaryngology-Head \& Neck Surgery, 126, 837-841 https://doi.org/10.1001/archotol.126.7.837

[8] Tay, H.L. (1995) Post-Operative Morbidity in Electrodissection Tonsillectomy. The Journal of Laryngology \& Otology, 109, 209-211. 
https://doi.org/10.1017/S0022215100129718

[9] Hultcrantz, E. and Ericsson, E. (2004) Pediatric Tonsillotomy with the Radiofrequency Technique: Less Morbidity and Pain. Laryngoscope, 114, 871-877. https://doi.org/10.1097/00005537-200405000-00016

[10] Toma, A.G., Blanshard, J. and Eynon-Lewis, N. (1995) Posttonsillectomy Pain: The First Ten Days. The Journal of Laryngology \& Otology, 109, 963-964. https://doi.org/10.1017/S0022215100131767

[11] Nelson, L.M. (2001) Temperature-Controlled Radiofrequency Tonsil Reduction: Extended Follow-Up. Otolaryngology-Head and Neck Surgery, 125, 456-461. https://doi.org/10.1067/mhn.2001.119441

[12] Nelson, L.M. (2000) Radiofrequency Treatment for Obstructive Tonsillar Hypertrophy. Archives of Otorhinolaryngology-Head \& Neck Surgery, 126, 736-740. https://doi.org/10.1001/archotol.126.6.736

[13] Ericsson, E., Graf, J. and Hultcrantz, E. (2006) Pediatric Tonsillotomy with RadioFrequency Technique: Long-Term Follow-Up. Laryngoscope, 116, 1851-1857. https://doi.org/10.1097/01.mlg.0000234941.95636.e6

[14] El tahan, A.E., Elzayat, S. and Hegazy, H. (2016) Adenoidectomy: Comparison between the Conventional Curettage Technique and the Coblation Technique in Pediatric Patients. The Egyptian Journal of Otolaryngology, 32, 152-155. https://doi.org/10.4103/1012-5574.186528 